\title{
Grupo Operativo como Estratégia de Autocuidado para Portadores de Diabetes Mellitus Tipo 2
}

\author{
Tiara Cunha Silva, ${ }^{1}$ Davyd Christyan de Menezes Ferreira Leal, ${ }^{2}$ Juliana Ramos Bruno ${ }^{3}$
}

\begin{abstract}
RESUMO
Objetivo: Conhecer a percepção dos diabéticos sobre a patologia, o tratamento e o autocuidado antes e após a instituição de um grupo operativo. Métodos: Trata-se de um estudo do tipo descritivo, longitudinal de abordagem qualitativa, realizado com portadores de Diabetes Mellitus tipo 2 cadastrados na área de abrangência da Equipe 07 da Unidade Saúde da Família 712 Sul no município de Palmas-Tocantins, que tiveram adesão a três ou mais encontros do grupo operativo. Foram realizados cinco encontros do grupo no período de maio a agosto de 2015. A coleta de dados ocorreu por meio de entrevista semiestruturada antes e após a criação do grupo operativo. Este estudo foi aprovado pelo Comitê de Ética e Pesquisa do Ceulp-Ulbra sob parecer № 1063446. Resultados e Discussão: Aceitaram participar da pesquisa 17 diabéticos e destes, 9 participantes tiveram adesão a três ou mais encontros do grupo operativo. As falas foram estudadas com base na Análise de Conteúdo e originaram as seguintes categorias: Conhecimento acerca da doença, Mudança no estilo de vida, Dificuldades encontradas para seguir o tratamento e Sentimentos diante da doença. Conclusão: Os resultados do estudo demonstraram que a instituição do grupo operativo realizado a partir de abordagens lúdicas, dialógicas, participativas, com o favorecimento da escuta, reflexão e problematização da realidade do usuário, proporcionou aos diabéticos uma melhor compreensão acerca do seu processo saúde-doença, incorporando mudanças de comportamento significativas para melhoria da qualidade de vida.
\end{abstract}

Palavras-chave: Diabetes mellitus. Autocuidado. Educação em saúde.

$$
\text { OPERATING GROUP AS A SELF-CARE STRATEGY FOR DIABETES CARRIERS MELLITUS TYPE } 2
$$

\begin{abstract}
Objective: To know the perception of diabetes on the pathology, treatment and self-care before and after the implementation of an operating group. Methods: This is a descriptive study, longitudinal qualitative study conducted with patients with type 2 diabetes mellitus registered in team coverage area 07 of the Health Unit Family 712 South in Palmas, Tocantins, who had three or more operating group meetings with support. The group had five meetings in the period from May to August 2015. The data were collected through semi-structured interviews before and after the implementation of the operative group. This study was approved by the Research Ethics Committee of Ceulp-Ulbra under report number 1063446. Results and Discussion: Seventeen diabetic people agreed to participate in the research. Nine of these participants took part to three or more operating group meetings. The speeches were analyzed based on content analysis that gave the following categories: Knowledge about the disease, change in lifestyle, found difficulty to keep on the treatment and feelings about the disease. Conclusion: The results of the study showed that the implementation of the operative group realized from playful, dialogic and participatory approaches, with the encouragement of listening, reflection and questioning of the user reality, that provided to diabetics a better understanding of their health-disease process, incorporating significant changes in behavior to improve the quality of life.
\end{abstract}

Keywords: Diabetes mellitus. Self-care. Health education.

RECEBIDO EM: 29/2/2016

MODIFICAÇÕES REQUERIDAS EM: 24/2/2017

ACEITO EM: 27/8/2019

\footnotetext{
Enfermeira do trabalho do Instituto Federal de Educação, Ciência e Tecnologia do Tocantins-IFTO. Mestranda do Programa de Pós-Graduação em Ciências da Saúde da Universidade Federal do Tocantins. tiaracunha@yahoo.com.br

${ }^{2}$ Enfermeiro. Especialista em Saúde da Família pela Universidade Federal de Goiás-UFG. dyleal@gmail.com

${ }^{3}$ Nutricionista. Mestre em Nutrição e Saúde pela Universidade Federal de Goiás-UFG. julianabruno@msn.com
} 


\section{INTRODUÇÃO}

O Diabetes Mellitus tipo 2 é uma doença crônica em expansão em todo o mundo, e suas complicações a longo prazo representam um importante problema de saúde pública, tendo em vista que para o tratamento há necessidade de incorporação de tecnologias de alto custo, onerando excessivamente o sistema de saúde (SOCIEDADE..., 2009).

Segundo Lima-Costa et al. (2007), estima-se que pelo menos 171 milhões de pessoas tenham a doença, podendo alcançar em 2030 o quantitativo de 366 milhões de pessoas. Ainda segundo o autor, suas complicações correspondem a 4 milhões de óbitos por ano, equivalente a $9 \%$ da mortalidade mundial total.

O desenvolvimento da doença não ocorre de forma repentina e existe um conjunto de fatores que estão relacionados à sua progressão, como a alimentação inadequada, obesidade, sedentarismo, disposição genética, estresse, entre outros. Dessa forma, o estilo de vida influencia no aparecimento da doença, no controle metabólico e na prevenção das complicações.

Por essas razões, um dos maiores desafios para os profissionais de saúde em relação à pessoa com diabetes consiste em educar para que as mudanças comportamentais aconteçam e se mantenham ao longo da existência, uma vez que os pacientes possuem hábitos de vida muitas vezes arraigados culturalmente e associados a questões subjetivas relacionadas ao seu modo de vida (SOCIEDADE..., 2009; OLIVEIRA et al., 2011).

Durante a realização do diagnóstico situacional da área de abrangência da equipe 07 da Unidade Saúde da Família (USF) 712 Sul, realizado como parte do plano de trabalho proposto pelo Programa de Residência em Saúde da Família e Comunidade entre os meses de junho e agosto de 2014 , foi verificado que os pacientes diabéticos mostravam dificuldade na adesão e manutenção de atitudes que produzam mudança no estilo de vida, e embora apresentassem algum tipo de informação sobre seu problema de saúde, possuíam um déficit de conhecimento sobre a doença.

Este fato foi percebido durante as consultas de enfermagem, que demonstraram de um modo geral que a maioria dos diabéticos possuía informações básicas sobre seu problema de saúde, porém não apresentavam um controle glicêmico adequado. A discrepância entre ter informação a respeito da doença e seu tratamento e conseguir controlar o Diabetes Mellitus aponta para a diferença essencial entre conhecimento e adesão. Enquanto o conhecimento é ra- cional, a adesão é um processo complexo que envolve fatores biossociais, emocionais e barreiras concretas, de ordem prática e logística (JESUS et al., 2008).

Desenvolver ações de promoção da saúde desafia os serviços na área a superarem a fragmentação do cuidado e irem em direção à perspectiva da atenção integral às pessoas em suas necessidades, numa relação dialógica do cuidar/ser cuidado, do ensinar/ aprender. Traz os serviços à reflexão de que necessitam participar ativamente das soluções dos problemas de saúde levantados conjuntamente com as comunidades (BRASIL, 2010).

Diante deste cenário, compreendeu-se a necessidade de intervir nas ações desenvolvidas com os portadores de Diabetes Mellitus tipo 2, por meio da criação de um grupo operativo, com o objetivo de conhecer a percepção dos diabéticos sobre a patologia, o tratamento e o autocuidado antes e a após a criação do grupo.

\section{METODOLOGIA}

Trata-se de um estudo do tipo descritivo, longitudinal de abordagem qualitativa, tendo como participantes usuários portadores de Diabetes Mellitus tipo 2 que tiveram adesão e assiduidade a três ou mais encontros do grupo operativo. A pesquisa foi desenvolvida em uma Unidade Saúde da Família do município de Palmas-Tocantins, por ser cenário de prática da Residência Multiprofissional em Saúde da Família e Comunidade.

O grupo operativo apresenta-se como instrumento de transformação da realidade, seus integrantes passam a estabelecer relações grupais que vão se constituindo à medida que começam a partilhar objetivos comuns, a ter uma participação criativa e crítica e a poder se perceber como interagem e se vinculam (PICHON-RIVIÈRE, 2009).

A coleta de dados ocorreu mediante entrevista semiestruturada, observação participante e o uso de dados secundários, de modo a possibilitar uma maior abrangência da análise dos dados. Primeiramente, antes da instituição do grupo, foi realizada a entrevista na residência de cada paciente diabético que aceitou participar da pesquisa, por meio de visitas domiciliares. Posteriormente, após a realização do grupo, foi realizada a entrevista com os participantes que tiveram adesão a três ou mais encontros, a fim de compreender os possíveis benefícios trazidos pelo grupo para cada um. As falas dos participantes foram gravadas e transcritas na íntegra. Para garantir o anonimato, adotou-se o nome de frutas, escolhidas por eles em uma dinâmica realizada nos encontros. 
Foram realizados cinco encontros do grupo operativo na USF 712 Sul com a participação da equipe multiprofissional e de outros profissionais da saúde. Os encontros ocorreram com intervalos de três semanas no período de maio a agosto de 2015. A cada encontro foram abordados temas direcionados ao autocuidado e à promoção da saúde, a partir da utilização de uma abordagem lúdica, recreativa e integradora para facilitar a interação entre os usuários e profissionais de saúde, tornando o ambiente um campo de saber significativo para a troca de experiências.

No total, 17 diabéticos aceitaram participar da pesquisa, e destes, 9 participantes tiveram adesão a três ou mais encontros do grupo operativo, que tiveram duração média de 1 h a 1 h e 20 min.

Os dados foram submetidos à análise de conteúdo, seguindo as seguintes etapas: pré-análise, quando se realizou a leitura das transcrições das sessões grupais, buscando maior contato com o conteúdo dos dados; exploração do material, com leitura aprofundada e repetitiva com vistas a identificar as unidades de registro, bem como classificar e codificar os dados para a conformação de categorias; e, finalmente, o tratamento e interpretação das categorias obtidas (MINAYO, 2006).

O projeto de pesquisa foi aprovado pelo Comitê de Ética em Pesquisa do Centro Universitário Luterano de Palmas-TO (Ceulp/Ulbra), mediante o parecer no 1063446.

\section{RESULTADOS E DISCUSSÃO}

Com base nos dados da entrevista semiestruturada, foi possível identificar o perfil sociodemográfico da população estudada quanto ao sexo, à idade, à escolaridade, ao estado civil, à renda familiar e ao tempo de diagnóstico do Diabetes. O perfil predominante dos participantes constituiu-se de: Ensino Fundamental incompleto $(77,7 \%)$, sexo feminino $(66,6 \%)$, aposentados $(55,5 \%)$, casados $(55,5 \%)$, variação de idade entre 27 e 76 anos, com a idade média de 60 anos. A renda familiar foi de um a três salários mínimos e o tempo de diagnóstico da doença variou de 1 mês a 13 anos.

\section{Descrição dos Encontros}

\section{1을 Encontro}

O primeiro encontro do grupo foi voltado para o conhecimento do Diabetes Mellitus, suas causas, sinais e sintomas, tratamento, complicações, além de promover a integração do grupo. Iniciou-se com a confecção dos crachás com o nome de cada participante, em seguida a avaliação antropométrica, mensuração do dextro, circunferência abdominal, pressão arterial e questões pertinentes a hábitos de vida, que seguiram sendo registrados ao início de cada um dos encontros subsequentes. Com o intuito de buscar uma maior adesão e compromisso entre os integrantes do grupo, foi pactuada a duração dos encontros, o melhor horário para iniciá-los, as temáticas propostas e a avaliação do grupo ao final. Em seguida, em forma de círculo, iniciou-se a apresentação de cada participante por meio da dinâmica "quebra-gelo". A partir desse momento o tema proposto foi discutido pela enfermeira residente da Estratégia Saúde da Família, que utilizou objetos e figuras para melhor compreensão e entendimento por parte dos participantes. A participação dos integrantes do grupo foi um quesito observado e avaliado positivamente neste encontro, pois muitas eram as dúvidas sobre o agravo e às vezes os próprios colegas respondiam, gerando a troca de experiências/saberes que contribuíram para o enriquecimento do grupo. Neste primeiro encontro, dos 14 diabéticos entrevistados antes da inicialização do grupo, 13 participaram da atividade.

\section{$2^{\circ}$ Encontro}

O segundo encontro do grupo, que teve a participação de uma nutricionista, contou com 14 participantes, quando foi abordada a importância da alimentação saudável, a fim de estimular a construção de novos sentidos para a conduta alimentar. De acordo com o relato do grupo, foi um dos encontros mais esperados. Discutiu-se quais os alimentos e a quantidade que costumavam ingerir nas principais refeições do dia, anotando-os no quadro, promovendo uma melhor integração no grupo, estimulando a identificação e similaridades entre os participantes, mas sempre respeitando as particularidades de cada um. A atividade foi desenvolvida utilizando-se figuras cinematográficas (frutas, arroz, feijão, carne, bolos, doces, ovos, legumes, entre outros), talheres de medidas, diferentes tipos de pratos, além de entregar para cada participante uma lista de substitutos, como instrumento de discussão sobre cada tópico da lista. Esta metodologia proporcionou-lhes uma melhor visualização e compreensão do tema proposto. As dúvidas foram surgindo ao longo da discussão, e ao final do encontro muitos participantes permaneceram no local para saná-las com a nutricionista, o que revela um grande interesse acerca do assunto. Após a realização da primeira reunião, outros 3 diabéticos solicitaram 
participar dos encontros e foram integrados ao grupo, devido às possibilidades de adesão a três encontros, totalizando 17 participantes.

\section{3으 Encontro}

No terceiro encontro, que contou com a participação de 8 integrantes, foi abordada a importância da atividade física, tendo como facilitadores dois profissionais de Educação Física. O objetivo deste encontro foi promover e estimular a troca de experiências, significados e representações atribuídos à realização de exercícios físicos. Inicialmente os profissionais apresentaram-se, fizeram questionamentos sobre a prática da atividade física para os participantes a fim de avaliar o grau de atividade e seu conhecimento. A partir disso foram discutidos todos os aspectos que envolvem a atividade física e foram repassadas orientações sobre o tipo, duração e intensidade da atividade para cada participante, de acordo com suas limitações. Alguns questionaram sobre as dificuldades que possuíam, sejam elas físicas, temporais, ou de condicionamento, e os próprios participantes discutiam estratégias que poderiam ser acatadas por eles. Outros compartilharam a experiência positiva que tiveram com a prática de atividade física, bem como os benefícios que tiveram com o corpo e com o melhor controle da doença. Ao final do encontro foi realizada a prática de alongamento a fim de incentivá-los à prática corporal. Após o encerramento alguns participantes deslocaram-se até a academia ao ar livre que se localiza na entrada da USF e praticaram as orientações recebidas, demonstrando a efetividade do encontro.

\section{4o Encontro}

O quarto encontro foi destinado a abordar a importância do tratamento medicamentoso, e contou com a participação do enfermeiro de saúde da família como facilitador deste processo. Inicialmente foi pedido para cada integrante relatar se faz uso de algum medicamento para o Diabetes, o tipo de medicação, a frequência e o tempo de uso. Em seguida discutiram sobre as dificuldades e facilidades encontradas no uso dos medicamentos, além de quebras de mitos e tabus. Logo em seguida foi feita uma apresentação autoexplicativa sobre o uso da insulina com cada participante. Neste encontro 8 participantes aderiram ao grupo operativo.

\section{$5^{\circ}$ Encontro}

O quinto e último encontro, facilitado por um psicólogo, contou com a participação de 10 integrantes, sendo abordadas questões referentes à autoesti- ma e à importância do "eu" no processo do autocuidado. Iniciou-se com apresentação por meio de uma dinâmica interativa e logo em seguida se discutiu o dia a dia dos participantes, sempre incentivando-os a relatarem suas dificuldades, suas limitações, os sucessos, os fracassos com relação à doença, durante toda a vida. Logo após utilizou-se um estudo de caso em quadrinhos sobre o dia a dia de um diabético, relacionando os aspectos biológicos, sociais e mentais. Os participantes identificaram-se muito com o personagem, possibilitando reflexões de suas práticas diárias: como lidar com o insucesso, com as dificuldades, com a importância do "eu" no processo do autocuidado. Ao final do encontro o grupo foi elogiado pela perseverança, pelo empenho, pelo início das modificações do seu estilo de vida e pela confiança na equipe saúde da família. Ao final, os pacientes avaliaram que a dinâmica do grupo proporcionou um importante espaço para falar e escutar e maior interação entre os participantes. A importância deste estudo repousa em seu potencial de permitir a reflexão aos participantes, a troca de experiências e a construção de conhecimentos por intermédio de uma perspectiva dialógica e interativa, em que os problemas e soluções são compartilhados, ampliando assim os horizontes do pensar, do sentir e do agir. Percebeu-se que além do conhecimento obtido, os usuários sentiram-se estimulados pela participação de outros participantes e profissionais de saúde e por estarem em um local com pessoas que possuem o mesmo agravo. Era perceptível a troca de experiências, de saberes, de sucesso, de fracasso de cada participante, propiciando a promoção ao autogerenciamento do cuidado.

\section{APRESENTAÇÃO DAS CATEGORIAS}

Com vistas a responder ao objetivo que norteou a execução do presente estudo, a partir da análise temática das transcrições das sessões grupais foram elaboradas quatro categorias e duas subcategorias: Conhecimento acerca da doença (tratamento e complicações da doença), Mudança no estilo de vida, Dificuldade encontrada para seguir o tratamento e Sentimentos em relação à doença.

\section{Conhecimento da Doença}

No início das atividades do grupo operativo foi possível observar pouco ou quase nenhum conhecimento acerca do Diabetes Mellitus, como relatado pelos participantes:

"Eu não responderia nada. Porque não sei de nada" (Melão). 
"Essa doença [...] eu não sei nem explicar o que que é essa doença, que tá dando né quase todo mundo" (Melancia).

"É uma doença que a gente tem que ter limite, a gente não pode comer certas coisas, tem que ter o cuidado" (Maçã).

Após o último encontro do grupo operativo, contudo, observou-se um importante avanço no conhecimento sobre o agravo, sua significância e cuidados necessários, apesar de não conseguirem reproduzir de modo fiel as informações trabalhadas nos encontros:

"É uma doença degenerativa que através dela se você não cuidar, causa outros tipos de doenças" (Laranja).

"Eu acho que a diabetes, pelo que eu vejo as pessoas, os médicos falar e as pessoas e as reunião que a gente teve lá no posto, né?, com vocês, eu acho que a diabetes é pior do que um câncer, se você brincar muito ela mata mais rápido do que um câncer" (Tangerina).

"Diabetes é uma coisa perigosa, coisas que você comia hoje você não pode comer, muitas coisas, né? Assim, pode comer moderadamente, comer assim um pouquinho de um, um pouquinho de outro, porque se não, tem que ter muito cuidado" (Banana).

A primeira impressão ao analisar as falas nos leva a entender que as informações sobre a doença foram insuficientes para a correta compreensão do processo fisiopatológico, mas ao nos debruçarmos sobre o impacto na qualidade de vida dos diabéticos, constatamos que os conhecimentos apresentados ao final das atividades mostram ser de grande relevância na compreensão acerca da importância do cuidado que devem ter no dia a dia para o controle da doença e melhoria da qualidade de vida.

Nesse sentido, a informação é uma ferramenta preciosa, tendo se em vista que, quando as pessoas têm pouco conhecimento em relação à doença e à dinâmica do controle glicêmico, resistem a incorporar os comportamentos de autocuidado, o que dificulta a adesão terapêutica e, consequentemente, o controle dos níveis glicêmicos. Desta forma destaca-se a educação para o autocuidado como fator primordial para os indivíduos diabéticos, uma vez que é a partir dele que os pacientes poderão conhecer melhor o seu processo saúde-doença e melhorar seus hábitos de vida, com objetivo de chegar a níveis normais de glicose sanguínea (TORRES; PACE; STRADIOTO, 2010).

\section{Tratamento da Doença}

O tratamento do Diabetes Mellitus tem como meta o controle glicêmico. Nesta perspectiva, torna-se necessário se dispor de boas estratégias para a obtenção e manutenção de níveis glicêmicos próximos da normalidade no longo prazo.

No início do primeiro encontro a percepção dos participantes sobre tratamento da doença foi predominantemente medicamentosa, não incorporando outros fatores não medicamentosos, como atividade física, a alimentação adequada e comorbidades associadas:

"Esse tratamento eu tomo 2 tipos de medicamentos, né? O glibenclamida pela manhã em jejum e depois do almoço tomo uma metformina e depois da janta eu tomo outra metformina" (Laranja).

"Também não sei [...] tem que fazer os exames pro médico olhar e dizer como que tá" (Melão).

"Tomar o medicamento, né" (Manga).

"O tratamento é a pessoa deixar de comer muito sal, açúcar, gordura" (Melancia).

Segundo a Sociedade Brasileira de Diabetes (2009), a adoção de um estilo de vida saudável, com a prática regular de atividade física e a ingestão de dieta adequada é praticamente duas vezes mais efetiva que o tratamento farmacológico no controle do Diabetes.

O tratamento efetivo da doença depende quase que exclusivamente da pessoa que convive com a enfermidade. Ela exerce o controle glicêmico quando conta com o conhecimento, as habilidades, as atitudes e também a consciência necessária para influenciar a sua conduta e consequentemente a melhoria na sua saúde (FUNNEL et al., 1991), ressaltando-se as informações e orientações a respeito dos conhecimentos e atitudes acerca da doença como fundamentais no favorecimento de mudanças de comportamento associados à dieta e à prática de atividade física.

O desenvolvimento do grupo operativo revelou a importância das práticas educativas na promoção da saúde, possibilitando uma maior compreensão acerca da complexidade do tratamento e controle da doença, incorporando outros elementos, possibilitados pelas discussões e atividades realizadas durante os encontros:

"É feito através de medicamentos e tem um remedinho chamado insulina, né? Que esse é através de aplicação com a agulha [...] e cuidar da alimentação, controle de alimentação, há o 
exercício físico que tô fazendo também, que tô fazendo todo dia, minha fia, agora $2 x$ por dia" (Laranja)

"O tratamento você tem suas restrições alimentares, diariamente, e tomar os remédios necessários indicados pelo médico e a atividade física" (Melão).

"Ah ]...] pra tratar é simples, é fazer caminhada, é cuidar da alimentação, tomar os remédios certinho e estar sempre fazendo caminhada" (Maçã).

\section{Complicações da Doença}

Um dos pontos mais marcantes ao se comparar com o nível de conhecimento antes e após a realização dos encontros foi acerca das complicações da doença. Em geral, a carga negativa e as consequências do tratamento inadequado sempre foram pauta no relato dos participantes, mesmo antes do início das atividades.

A percepção negativa que a pessoa tem do Diabetes pode ter relação com o modo como os profissionais de saúde conduzem o tratamento e o cuidado com a saúde, situando as proibições como centro das orientações, o enfoque individual e medicalizador, com pouca importância para as atividades de educação em saúde no cotidiano das práticas sanitárias.

"Acho que ela complica muitas coisas na pessoa, por exemplo, as vistas e o intestino, outras coisas mais, né?" (Melão).

"Primeira coisa é a cegueira, atinge os ossos, tem vez que atinge o corpo todo, cai o cabelo, cê ta entendendo? Tem que ter cuidado para não se machucar" (Tangerina).

Muitos estudos apontam para a necessidade de melhor capacitação dos profissionais de saúde para orientações aos portadores de Diabetes Mellitus que ultrapassem o tratamento meramente medicamentoso, e também para o fato de que a ausência de uma equipe multiprofissional favorece a vulnerabilidade dos serviços de saúde quanto à promoção de hábitos de vida saudáveis preconizado pela Sociedade Brasileira de Diabetes Mellitus e pela Organização Mundial da Saúde. Faz-se relevante, portanto, uma equipe de saúde multiprofissional e abordagem integral como elementos técnicos capazes de proporcionar uma meIhor qualidade da assistência prestada ao portador de Diabetes Mellitus tipo 2.

Após a finalização das atividades do grupo operativo, verifica-se que a carga negativa continua presente no discurso dos participantes, porém alguns ele- mentos, como a possibilidade de controle, fazem-se presente, ampliando a compreensão do cuidado diário e interferência do estilo de vida nas consequências trazidas pela doença:

"Olha, as complicações que a gente pode ter sono, muita urina, se machucar custa sarar, é dificil, muito custoso, cegueira e várias outras coisas" (Melão).

"Ah, principalmente ficar cega, afeta os rins também e a autoestima, né, da pessoa fica muito baixa" (Maçã).

"Você pode ter machucados que não saram rápido, se você não tomar os remédios na hora certa você tem quedas de glicemia, ou dependendo do que você come durante o dia ela pode ficar controlada ou alterar" (Laranja).

Segundo Costa et al. (2011), os programas de educação com maiores êxitos são os que possuem abordagem multiprofissional, que auxiliam a pessoa com diabetes no seu próprio cuidado, por meio de instrumentos que habilitem para a tomada de decisão consciente, relacionada ao cuidado e tratamento da doença crônica. Esses são subsídios importantes para olhar a doença crônica como parte integrante da vida e não como um fator que irá interferir nela. Assim, as ações de educação em saúde devem partir da concepção de que, mesmo possuindo uma doença crônica, as pessoas podem viver de forma mais saudável, melhorando a qualidade de vida.

Desta forma, os indivíduos devem ter a oportunidade de conhecer e controlar os fatores determinantes da sua saúde, estando entre os principais elementos capacitantes o acesso à informação, o desenvolvimento de habilidades para viver melhor e a oportunidades para fazer escolhas mais saudáveis (BUSS, 2003).

\section{Mudança no Estilo de Vida}

É perceptível o descontentamento dos participantes quando se referem à mudança no estilo de vida perante as necessidades impostas pela doença antes da instituição do grupo operativo, como pode ser observado nos seguintes relatos ao serem questionados sobre a mudança no estilo de vida:

"E como mudou [...]mudou tudo! Mudou a alimentação, mudou o modo de viver, você fica completamente diferente" (Banana).

"Teve [ ...] primeiramente mudou assim [...] a minha convivência, mudou a minha mente, você tá entendendo? Só em saber em dizer assim não, 
eu não posso fazer isso, não, eu não posso fazer aquilo, eu tenho isso...isso aí já é uma mudança, né? Já tenho um cuidado" (Tangerina).

"Mudou [...] principalmente a maneira de se alimentar, e o que eu posso fazer pra melhorar essa alimentação" (Maçã).

Segundo Silva (2001), doença é considerada uma entidade processual causada por diversos fatores, mas a maneira de vê-la está relacionada com as experiências das pessoas em seu ambiente cultural permeado de significados. Os significados são constituídos com suporte em experiências vivenciadas, pois diferentes significados surgem de acordo com a história pessoal de cada um.

O diagnóstico de Diabetes tem um impacto profundo na vida do paciente. Lidar com um tratamento contínuo e com as complicações desencadeadas pelo controle metabólico insatisfatório é muito difícil para o diabético. O sentimento de impotência e revolta dificulta o enfrentamento e o convívio com as demandas diárias que a doença impõe. Assim, o apoio psicológico, o suporte e os esclarecimentos oferecidos por todos os profissionais da equipe são identificados como essenciais para fortalecer os pacientes a desenvolverem estratégias de enfrentamento desde o estabelecimento do diagnóstico (PERES, 2006).

A compreensão trazida por Peres pode ser observada ao término das atividades do grupo operativo, quando foi possível identificar um avanço significativo acerca da mudança no estilo de vida, incorporando o autocuidado como instrumento imprescindível para melhoria da qualidade de vida.

\begin{abstract}
"Assim, eu me cuidei mais, fiquei mais esperta né, cuidei mais da alimentação, sempre que posso sair a pé eu faço, então mudou bastante a minha vida" (Abacaxi).
\end{abstract}

"Fiquei com muito medo, mas aí depois fui cuidando, tô cuidando, né? Através da alimentação, das caminhadas, exercícios físicos e os remédios" (Laranja).

A motivação para obter maior autonomia e meIhorar o controle da doença também está relacionada com o apoio da equipe de saúde, oferecendo suporte técnico, incentivo e apoio às mudanças de comportamento. Assim sendo, quando a equipe terapêutica tolera escolhas, informa sobre riscos, compreende as reações emocionais do paciente, ela propicia maiores possibilidades de adesão e aquisição de novos hábitos exigidos (ALMINO; QUEIROZ; JORGE, 2009).
Destaca-se a educação para o autocuidado como uma estratégia adequada e indicada para o tratamento dos indivíduos com Diabetes. Estudos mostram que para que ocorra um controle eficaz da glicemia, torna-se relevante a existência de programas educativos para orientar as habilidades de autocuidado (TORRES; PACE; STRADIOTO, 2010). Sendo assim, para Baggio, Mazzola e Marcon (2011), as mudanças no estilo de vida, sobretudo em relação à prática alimentar e de atividade física, constituem a base para o tratamento e o controle da doença.

As doenças crônicas, consideradas incuráveis e permanentes, exigem que o indivíduo ressignifique sua existência, adaptando-se às limitações, às frustrações e às perdas. Essas mudanças serão definidas pelo tipo de doença, pela maneira como se manifesta e como segue o seu curso, além do significado que o paciente e a família atribuem ao evento (PILGER; ABREU, 2007).

\section{Dificuldades Encontradas Para Seguir o Tratamento}

A maioria dos diabéticos relatou dificuldade do controle sobre a vontade e restrição de alimentos e veem a ida aos grupos como forma de aprendizado e incentivo na busca do controle da doença:

"Eu tenho dificuldade na alimentação, que eu gosto de comer demais e eu às vezes termino extrapolando" (Laranja).

"Ih, mas é muito [...] olha, é tanta coisa, porque a gente não pode comer nada gorduroso, nem salgado e nem nada de doce mesmo e um bocado de coisa que a gente não pode comer, por isso aí a dificuldade" (Abacaxi).

"Eu tenho dificuldade mais dentro da minha casa porque eu mexo com pessoa que não é sadia, ele não entende o que eu posso e o que eu não posso, é que nem raiva, quando eu passo raiva eu passo mal, eu não durmo na hora que eu tenho vontade. Só Deus vai acabar, essa paixão, de não ter o meu direito de divertir, de caminhar, andar pra onde eu quero, entendeu? (Tangerina).

Os relatos transcritos indicam que alguns participantes percebem o controle alimentar como um sofrimento, considerando-o uma meta de tratamento difícil de ser consolidada. Assim, exibem reações como a angústia diante das inúmeras "perdas" e restrições que vivenciam em seu cotidiano durante o longo processo de adoecimento até sentimentos de descrença e culpa por desobedecer às restrições e recomendações preconizadas pela equipe de saúde. 
Tais falas sinalizam a complexidade inerente à mudança dos hábitos alimentares, tendo-se em vista a diversidade de fatores envolvidos. Quando se pensa nos costumes alimentares de uma população, existem dificuldades de mudanças relacionadas a diversos fatores, tais como os hábitos condicionados, a rotina de horários, o valor cultural associado aos alimentos, além de questões socioeconômicas (PERES et al., 2007).

A percepção, no entanto, de que existem outros caminhos possíveis, podendo-se encontrar apoio e suporte para as tomadas de decisão junto a equipe de saúde para o enfrentamento das dificuldades impostas pela doença, os participantes, após o grupo operativo, passam a se colocar como protagonistas do processo do autocuidado, como sujeitos ativos, desenvolvendo a consciência crítica e a capacidade de intervenção na realidade:

"Não [...] graças a Deus não, porque pra isso nós temos os nossos médicos e nossos enfermeiros que ajudam a gente" (Melão).

"Não existe dificuldade para quem quer vencer" (Ameixa).

As condições responsáveis por grande parte da morbimortalidade em adultos são determinadas por hábitos e estilos de vida. A modificação desses aspectos não é facilmente obtida, pois demanda mudanças ou mesmo extinção de situações prazerosas, muitas vezes já incorporadas ao cotidiano e com frequência apoiadas socialmente. A alteração de alguns desses hábitos, entretanto, pode gerar significativa modificação na qualidade e expectativa da vida (STEIN; ZELMANOWICZ; LIMA, 2013).

Tais evidências mostram que a prática educativa como exercício contínuo para o desenvolvimento da autonomia dos sujeitos é fundamental na assistência ao paciente com doença crônica, pois muitos encontros interativos no processo de monitorização para o controle da doença favorecem o processo educativo voltado para o enfrentamento e resolução dos problemas práticos também reais da vida diária de cada um. A troca de experiências e a participação ativa dos sujeitos conferem segurança e autonomia para as tomadas de decisão (SILVA, 2001).

A promoção da saúde apresenta-se como estratégia de mudança nos modelos assistenciais, contribuindo para que os sujeitos possam melhor compreender o processo saúde-doença, sinalizando a construção de outras possibilidades e a configuração de novos saberes, melhorando a qualidade de saúde da população. Dessa forma os profissionais, sendo atuantes, firmes nesse processo de capacitação do indivíduo, irão contribuir com subsídios para que os pacientes se tornem sujeitos participantes do processo e assim minimizar os agravos decorrentes do Diabetes Mellitus (SILVA et al., 2009).

\section{Sentimentos Diante da Doença}

O sentimento de negação imposto em relação à doença foi muito marcante nas falas dos participantes antes do início do grupo operativo. Eles percebiam o Diabetes como algo difícil de conviver, sem perspectivas positivas diante das dificuldades enfrentadas em seu dia a dia:

"No começo eu fiquei, só que depois eu acostumei, porque [...] é melhor tá viva fazendo um tratamento do que não tá vivo, né? Eu penso assim, mas eu fiquei muito triste, fiquei sem saber como que eu ia sobreviver, porque o que eu vejo falar da diabetes é tanta coisa que passa na televisão que a gente ouve" (Laranja).

“Primeira coisa, só em você não ter assim [...] liberdade, cê tá entendendo? Não ter liberdade como que quero dizer [...] de boca, não tem liberdade fisicamente, eu faço tudo, mas eu sei que tô fazendo um tratamento, eu não posso fazer isso porque eu tô fazendo o tratamento" (Tangerina).

"Sim, fiquei, até porque eu gostava muito de comer meus doces, beber meus refrigerantes e eu tive que cortar" (Maçã).

Ao finalizar os encontros percebeu-se o empoderamento dos participantes acerca do autocuidado, com possibilidades positivas de conviver com uma doença crônica tendo qualidade de vida:

"O primeiro pensamento é que você não vai durar muito tempo, mas hoje em dia eu tenho outro pensamento que se eu cuidar, vai depender de mim, pra mim viver mais ou menos" (Laranja).

"Eu fiquei contrariado no começo, mas depois que eu senti que é uma doença que não tem cura, mas ninguém morre dela tendo cuidado" (Ameixa).

Observa-se, por meio das falas dos participantes, que apesar dos sentimentos negativos diante da doença que se instalou em suas vidas, o aprendizado de uma convivência saudável com a doença pode ser alcançado, seja por meio de uma aceitação passiva e conformista ou de um posicionamento mais ativo perante a doença e o tratamento, acreditando na possi- 
bilidade de reagir de forma mais serena às demandas emocionais e de agir de modo organizado para obtenção de melhor controle (OLIVEIRA et al., 2011).

Ao considerarmos os desafios impostos na vida da pessoa que recebe o diagnóstico e as dificuldades relacionadas à adoção das mudanças inerentes ao tratamento, a demanda por apoio profissional torna-se crescente. Nessa perspectiva, o atendimento em grupo propiciou um clima aberto para livres expressões de ideias e sentimentos, permitindo aos participantes relatarem suas experiências, examinando seus sentimentos mais genuínos e buscando desenvolver seus recursos para a elaboração das emoções mobilizadas (OSORIO, 2007).

Segundo a Sociedade Brasileira de Diabetes (2009), a educação em Diabetes evoluiu muito nos últimos anos e as técnicas atuais para o estímulo e treinamento do autocuidado utilizam um modelo mais focado no paciente, buscando promover mudanças de comportamento mais positivas. Só podemos considerar a educação em Diabetes efetiva se esta resultar em "mudanças e/ou aquisição de comportamentos"; caso contrário estaremos somente transmitindo informações. Estas mudanças foram notadas ao final do grupo operativo, a partir das avaliações antropométricas e do estilo de vida realizadas em cada encontro, com os seguintes resultados: $44,4 \%$ dos participantes perderam peso, diminuíram o dextro e passaram a realizar atividades físicas e 55,5\% diminuíram a circunferência abdominal.

Diante disso as pessoas com Diabetes Mellitus tipo 2 que participam ativamente do tratamento, assistidas por uma equipe capaz de fornecer os recursos, as orientações e o apoio necessários, podem obter o melhor nível de glicemia. Proporcionar a essas pessoas as ferramentas necessárias para o controle glicêmico é uma importante meta do tratamento, com o objetivo de retardar ou interromper as complicações micro e macrovasculares da enfermidade, ao mesmo tempo minimizando a hiperglicemia e o ganho excessivo de peso (ADA, 2010).

\section{CONSIDERAÇÕES FINAIS}

Considera-se que a instituição do grupo operativo realizado a partir de abordagens lúdicas, dialógicas, participativas, com o favorecimento da escuta, reflexão e problematização da realidade do usuário, proporcionou ao paciente diabético uma melhor compreensão acerca do seu processo saúde-doença, incorporando mudanças de comportamento significativas para melhoria da qualidade de vida. É sabido que inúmeras são as dificuldades para o enfrentamento desta enfermidade, mas quando se envolve educação de saúde de forma inovadora, este processo torna-se menos dificultoso, pois Ihes possibilita terem autonomia e empoderamento sobre seus hábitos de vida.

Dessa maneira, as atividades educativas de autocuidado para os diabéticos devem ser adequadas às características da população, contemplando as representações sociais e aspectos da formação e educação de adultos, na medida em que podem contribuir para a elaboração de novos entendimentos acerca da realidade da pessoa e para um melhor enfrentamento da doença.

A condução dos grupos realizada por uma equipe multidisciplinar e os materiais educativos utilizados possibilitaram uma reflexão e aprofundamento sobre o tema proposto, levando o usuário a refletir sobre o seu estilo de vida, fazendo escolhas saudáveis, a partir da construção do seu conhecimento, que é favorecida por um encontro afetivo.

Sendo assim, os grupos operativos tornam-se importantes ferramentas para o estímulo e orientação do autocuidado para o portador de Diabetes Mellitus tipo 2, além de fortalecer o vínculo entre o profissional e o usuário.

\section{REFERÊNCIAS}

ADA. American Diabetes Association. Standarts of medical care in diabetes - 2010. Diabetes Care, 33, (supp 1), 11-61. DOI: 10.2337/dc10-S011. Disponível em: http://care.diabetesjournals.org/content/33/Supplement_1/S11.extract\#. Acesso em: 2 fev. 2016.

ALMINO, M. A. F. B.; QUEIROZ, M. V. O.; JORGE, M. S. B. Diabetes Mellitus na adolescência: experiências e sentimentos dos adolescentes e das mães com a doença. Rev. Esc. Enf. USP, v. 43, n. 4, p. 760-767, 2009.

BAGGIO, S. C.; MAZZOLA, J. C.; MARCON, S. S. A vivência da pessoa com Diabetes após atendimento de urgência. Cogitare Enferm, v. 16, n. 2, p. 275-281, 2011.

BRASIL. Ministério da Saúde. Política Nacional de Promoção à Saúde. Brasília, DF: MS, 2010.

BUSS, P. M. Uma introdução ao conceito de promoção da saúde. In: CZERESNIA, D.; FREITAS, C. M. Promoção da saúde: conceitos, reflexões, tendências. Rio de Janeiro: Fiocruz. 2003.

COSTA, J. A. et al. Promoção da saúde e Diabetes: discutindo a adesão e a motivação de indivíduos diabéticos participantes de programas de saúde. Ciência e Saúde Coletiva, Rio de Janeiro, v. 16, n. 3, p. 2.001-2.009, mar. 2011.

FUNNELL, M. M. et al. Empowerment: an idea whose time has come in diabetes education. Diabetes Educator, 17(1), p. 37-41, 1991. 
JESUS, E. S. et al. Perfil de um grupo de hipertensos: aspectos biossociais, conhecimentos e adesão ao tratamento. Acta Paul. Enferm. São Paulo, v. 21, n. 1, p. 59-65, mar. 2008.

LIMA-COSTA, M. F. et al. Validade do diabetes auto-referido e seus determinantes: evidências do projeto Bambuí. Rev. de Saúde Pública, São Paulo, v. 41, n. 6, p. 947-953, dez. 2007.

MINAYO, M. C. O desafio do conhecimento: pesquisa qualitativa em saúde. São Paulo: Hucitec; Abrasco, 2006. 406p.

OLIVEIRA, N. F. et al. Diabetes Mellitus: desafios relacionados ao autocuidado abordados em grupo de apoio psicológico. Rev. Bras. Enferm. Brasília-DF, v. 64, n. 2, p. 301-307, mar./abr. 2011.

OSORIO, L. C. Grupoterapias: abordagens atuais. Porto Alegre: Artmed. 2007.

PERES, D. S. Comportamento alimentar de diabéticas. Rev. de Saúde Pública, São Paulo, v. 40, n. 2, p. 310-317, abr. 2006.

PERES, D. S. et al. Dificuldades dos pacientes diabéticos para o controle da doença: sentimentos e comportamentos. Rev. Latino-Am. Enfermagem, Ribeirão Preto, SP, v. 15, n. 6, 2007.

PICHON-RIVIÈRE, E. O processo grupal. 8. ed. São Paulo: Martins Fontes, 2009. 286p.
PILGER, C.; ABREU, I. S. Diabetes Mellitus na infância: repercussões no cotidiano da criança e de sua família. Cogitare Enferm., Guarapuava-PR, v. 12, n. 4, p. 494-501, out/dez. 2007.

SILVA, D. M. G. V. Narrativa do viver com Diabetes Mellitus: experiências pessoais e culturais. Florianópolis: UFSC. 2001.

SILVA, K. L. et al. Educação em enfermagem e os desafios para a promoção de saúde. Rev. Bras. Enferm., Belo Horizonte, MG, v. 62, n. 1, p. 86-91, 2009.

SOCIEDADE BRASILEIRA DE DIABETES. Cuidados de Enfermagem em Diabetes Mellitus. São Paulo: Departamento de Enfermagem da Sociedade Brasileira de Diabetes, 2009. $173 p$.

STEIN, A.; ZELMANOWICZ, A. M.; LIMA, A. K. Promoção da saúde e deteç̧ão precoce de doenças no adulto. In: DUNCAN, B. B.; SCHMIDT, M. I.; GIUGLIANI, E. R. J. et al. Medicina ambulatorial: condutas de atenção primária baseadas em evidências. 3. ed. Porto Alegre: Artmed, 2013.

TORRES, H. C.; PACE, A. E.; STRADIOTO, M. A. Análise sociodemográfica e clínica de indivíduos com diabetes tipo 2 e sua relação com o autocuidado. Cogitare Enferm, v. 15, n. 1, p. 48-54, jan./mar. 2010. 